\title{
Catabolism of mannitol in Lactococcus lactis MG1363 and a mutant defective in lactate dehydrogenase
}

\author{
Ana Rute Neves, ${ }^{1}$ Ana Ramos, ${ }^{1}$ Claire Shearman, ${ }^{2}$ Michael J. Gasson ${ }^{2}$ \\ and Helena Santos ${ }^{1}$
}

Author for correspondence: Helena Santos. Tel: +35121 4469829. Fax: +351214428766. e-mail: santos@itqb.unl.pt

\footnotetext{
${ }^{1}$ Instituto de Tecnologia Química e Biológica/ Universidade Nova de Lisboa, and Instituto de Biologia Experimental e Tecnológica, Rua da Quinta Grande, 6, Apt 127, 2780-156 Oeiras, Portugal

2 Institute of Food Research, Norwich Laboratory, Norwich Research Park, Colney, Norwich NR4 7UA, UK
}

\begin{abstract}
Mannitol metabolism in Lactococcus lactis MG1363 and in a derivative strain deficient in lactate dehydrogenase (LDH ${ }^{d}$ ) was characterized. Both strains had the ability to grow on mannitol as an energy source, although this polyol was a poorer substrate for growth than glucose. When compared to glucose, the metabolism of mannitol caused an NADH burden due to formation of an additional NADH molecule at the reaction catalysed by mannitol-1-phosphate dehydrogenase (MtI1PDH). This resulted in a prominent accumulation of mannitol 1-phosphate (Mt|1P) both in growing and resting cells, suggesting the existence of a severe bottleneck at MtI1PDH. Growth on mannitol induced the activity of MtI1PDH in both the LDH ${ }^{d}$ and MG1363 strains. The lower accumulation of MtI1P in mannitol-grown cells when compared to glucosegrown LDH ${ }^{\mathrm{d}}$ cells, as monitored by in vivo ${ }^{13} \mathrm{C}-\mathrm{NMR}$, reflects this induction. A clear shift towards the production of ethanol was observed on mannitol, indicating pressure to regenerate NAD+ when this substrate was used. A strategy to obtain a mannitol-overproducing strain is proposed.
\end{abstract}

Keywords: mannitol catabolism, L. lactis, in vivo ${ }^{13} \mathrm{C}-\mathrm{NMR}$

\section{INTRODUCTION}

The ability of several bacteria, such as Lactobacillus plantarum, some bifidobacteria, Escherichia coli and Streptococcus mutans to utilize mannitol as a primary energy source for growth has long been established (Chakravorty, 1964; de Vries \& Stouthamer, 1968; Maryanski \& Wittenberger, 1975). In the organisms examined, mannitol is transported via a specific phosphoenolpyruvate (PEP): mannitol-dependent phosphotransferase system $\left(\mathrm{PTS}^{\mathrm{Mt1}}\right.$ ) (Postma et al., 1993); the resulting mannitol 1-phosphate $(\mathrm{Mtl} 1 \mathrm{P})$ is subsequently converted to fructose 6-phosphate (F6P) by the activity of Mtl1P dehydrogenase (Mtl1PDH) (Chakravorty, 1964; Lee et al., 1981; Loesche \& Kornman, 1976; Rager et al., 1999; Streekstra et al., 1987). The production of mannitol and Mtl1P during glucose metabolism

Abbreviations: FBP, fructose 1,6-bisphosphate; F6P, fructose 6-phosphate; GAPDH, glyceraldehyde-3-phosphate dehydrogenase (EC 1.2.1.12); LDH, L-lactate dehydrogenase (EC 1.1.1.27); LDH ${ }^{d}$, lactate-dehydrogenasedeficient; Mtl1P, mannitol 1-phosphate; Mtl1PDH, mannitol-1-phosphate dehydrogenase (EC 1.1.1.17); PEP, phosphoenolpyruvate; PFK, 6-phosphofructokinase (EC 2.7.1.11) ; 3-PGA, 3-phosphoglycerate; PK, pyruvate kinase (EC 2.7.1.40); PTS ${ }^{\mathrm{Mtl}}$, mannitol phosphotransferase system. supports the view that the reduction of F6P to Mtl1P, concomitant with $\mathrm{NAD}^{+}$regeneration, is a useful pathway for the fulfilment of the redox balance in several organisms (Edwards et al., 1981; Ezra et al., 1983; Loesche \& Kornman, 1976; Neves et al., 2000; Rager et al., 1999; Rosenberg et al., 1984). In some Leuconostoc species, mannitol is produced from fructose by a mannitol dehydrogenase, in a process also coupled to the oxidation of NADH (Grobben et al., 2001; Dols et al., 1997), and in many fungi, mannitol is involved in a cycle of utmost importance both for NADPH biosynthesis and NADH oxidation (Hult et al., 1980).

Recently, we reported the production of mannitol and Mtl1P during glucose metabolism in cell suspensions of a lactate-dehydrogenase-deficient $\left(\mathrm{LDH}^{\mathrm{d}}\right)$ strain of $\mathrm{Lac}$ tococcus lactis (Neves et al., 2000). This metabolic peculiarity was rationalized as an alternative way to regenerate $\mathrm{NAD}^{+}$in the absence of the pivotal enzyme LDH. Interestingly, after glucose depletion, mannitol was taken up from the medium and converted mainly to ethanol. To the best of our knowledge, there are no reports in the literature concerning the ability of L. lactis to use mannitol as a substrate for growth; being more 
reduced than glucose, mannitol metabolism implies the formation of an extra NADH molecule that has to be reoxidized downstream of the pyruvate node.

Although mannitol is not important as a substrate in dairy sources, its presence in food products is desirable, since it can be converted in the human gut to short-chain fatty acids, which presumably confer protection against the development of colon cancer (van Munster \& Nagengast, 1993). Furthermore, it is a low-calorie sweetener that can replace sucrose (Furia, 1972) and a scavenger of free hydroxyl radicals (Rozenberg-Arska et al., 1985). Therefore, the production of mannitol by L. lactis could be exploited to obtain healthier foods. Mannitol has also been shown to act as an osmolyte (Kets et al., 1996; Luxo et al., 1993) and as a protector of L. lactis cells when subjected to drying (Efiuvwevwere $e t$ al., 1999). In spite of its physiological and biotechnological interest, mannitol metabolism has not been investigated in lactic acid bacteria, except for the oral pathogens (Yamada, 1987). A greater understanding of the pathways and regulatory mechanisms involved in mannitol metabolism is a requisite for the design of mannitol-overproducing strains.

In this work, we studied mannitol metabolism in L. lactis MG1363 and a derivative $\mathrm{LDH}^{\mathrm{d}}$ strain; growth parameters as well as intracellular metabolite pools were determined. The presence of mannitol led to a strong induction of Mtl1PDH activity and to the accumulation of Mtl1P and the production of high amounts of ethanol and formate. The pools of intracellular metabolites, Mtl1P, fructose 1,6-bisphosphate (FBP), 3-phosphoglycerate (3-PGA) and PEP in mannitol- or glucose-grown cells were monitored noninvasively by ${ }^{13} \mathrm{C}-\mathrm{NMR}$.

\section{METHODS}

Bacterial strains and growth conditions. L. lactis strains FI7851 (LDH ${ }^{\mathrm{d}}$ ) (Gasson et al., 1996) and MG1363 (parental strain) (Gasson et al., 1983) were grown at $30^{\circ} \mathrm{C}$ in a 21 fermenter (Bioflo IIc; New Brunswick) at pH 6.5 as described previously (Neves et al., 2000). The chemically defined medium described by Poolman \& Konings (1988), containing $55 \pm 2 \mathrm{mM}(1 \%$, w/v) glucose or $60 \pm 1 \mathrm{mM}(1 \%$, w/v) mannitol, was supplemented with erythromycin $\left(5 \mu \mathrm{g} \mathrm{ml}^{-1}\right)$ for the growth of the $\mathrm{LDH}^{\mathrm{d}}$ strain, which contains an erythromycin reporter gene. Growth was evaluated by measuring $\mathrm{OD}_{600}$ and calibrating against cell dry weight measurements.

Quantification of fermentation products. Samples $(5 \mathrm{ml})$ of the $\mathrm{LDH}^{\mathrm{d}}$ or MG1363 cultures grown in medium containing mannitol or glucose were taken at different growth stages, centrifuged $\left(2000 \mathrm{~g}, 5 \mathrm{~min}, 4^{\circ} \mathrm{C}\right)$ and supernatant solutions were stored at $-20^{\circ} \mathrm{C}$ until analysis by HPLC using a refractive index detector (LKB2142). Glucose, mannitol, acetate, ethanol, formate, lactate, acetoin and 2,3-butanediol were quantified using an $\mathrm{HPX}-87 \mathrm{H}$ anion exchange column (Bio-Rad) at $60{ }^{\circ} \mathrm{C}$, with $5 \mathrm{mM} \mathrm{H}_{2} \mathrm{SO}_{4}$ as the elution fluid and a flow rate of $0.5 \mathrm{ml} \mathrm{min}^{-1}$ (Hugenholtz \& Starrenburg, 1992).

Preparation of ethanol extracts and determination of intracellular phosphorylated metabolites by ${ }^{31} \mathrm{P}-\mathrm{NMR}$. Ethanol extracts of the $\mathrm{LDH}^{\mathrm{d}}$ and MG1363 strains were prepared as described previously by Ramos et al. (2001). The dried extracts were dissolved in $4 \mathrm{ml} \mathrm{H}_{2} \mathrm{O}$ containing $5 \mathrm{mM}$ EDTA and $2 \cdot 5 \%(\mathrm{v} / \mathrm{v}){ }^{2} \mathrm{H}_{2} \mathrm{O}$ (final $\mathrm{pH}$ approximately $7 \cdot 2$ ). Assignment of resonances and quantification of phosphorylated metabolites was based on previous studies (Ramos \& Santos, 1996; Ramos et al., 2001) or by spiking the NMR samples with the suspected pure compounds. The reported values for intracellular phosphorylated compounds are means of two independent growth experiments and the accuracy varied from 10 to $15 \%$.

In vivo NMR experiments and quantification of metabolites. Cells were grown as described above on medium containing mannitol or glucose and harvested in the mid-exponential growth phase and suspended in $50 \mathrm{mM}$ potassium phosphate buffer ( $\mathrm{pH} \mathrm{6.5)} \mathrm{to} \mathrm{a} \mathrm{protein} \mathrm{concentration} \mathrm{of} \mathrm{approximately}$ $13 \mathrm{mg}$ protein $\mathrm{ml}^{-1}$. In vivo NMR experiments were performed using the on-line system described previously (Neves et al., 1999). $\left[1-{ }^{13} \mathrm{C}\right]$ Glucose $(20 \mathrm{mM})$ or $\left[1-{ }^{13} \mathrm{C}\right]$ mannitol $(19 \mathrm{mM})$ were supplied to the cell suspension and the timecourse for their consumption, product formation and intracellular metabolite pools was monitored in vivo. When the substrate was exhausted and no changes in the resonances of intracellular metabolites were observed, an NMR sample extract was prepared as reported previously (Neves et al., 1999, 2002). The end products, lactate, acetoin, acetate, 2,3butanediol, ethanol and formate, were quantified in the NMR sample extract by ${ }^{1} \mathrm{H}-\mathrm{NMR}$ in a Bruker AMX300. The concentration of intermediates that remained inside the cells (pyruvate, aspartate, succinate, alanine) was determined in fully relaxed ${ }^{13} \mathrm{C}$ spectra of the NMR sample extracts as described by Neves et al. (2002).

For quantification of the intracellular metabolites, correction factors were determined, allowing the conversion of resonance areas into concentrations. The correction factor for FBP $(0 \cdot 73 \pm 0 \cdot 04)$ was obtained as described previously (Neves et al., 1999); a factor of $0.65 \pm 0.03$ was determined for mannitol and Mtl1P as reported by Neves et al. (2000). Metabolite concentrations were calculated using a value of $2.9 \mu \mathrm{l}(\mathrm{mg}$ protein $)^{-1}$ for the intracellular volume (Poolman et al., 1987). The concentration limit for detection of intracellular metabolites under the conditions used to acquire in vivo spectra (30 s total acquisition time) was $3-4 \mathrm{mM}$. The values shown are means of two to four experiments and the accuracy varied between 2 (end products) and $15 \%$ in the case of intracellular metabolites with concentrations below $5 \mathrm{mM}$.

NMR spectroscopy. ${ }^{13} \mathrm{C}$ or ${ }^{31} \mathrm{P}$ NMR spectra were acquired at 125.77 or $202.45 \mathrm{MHz}$ on a Bruker DRX500 spectrometer. All in vivo experiments were run using a quadruple nuclei probe head at $30^{\circ} \mathrm{C}$, as described previously (Neves et al., 1999). For the quantitative analysis of NMR sample extracts by ${ }^{13} \mathrm{C}$ NMR, a repetition delay of $60.5 \mathrm{~s}$ was used. The ${ }^{31} \mathrm{P}-\mathrm{NMR}$ spectra of the ethanol extracts were obtained as described by Ramos et al. (2001). For the determination of LDH activity in cell extracts, lactate production was monitored by ${ }^{1} \mathrm{H}-\mathrm{NMR}$ using a pulse width of $6 \mu \mathrm{s}\left(90^{\circ} \mathrm{flip}\right.$ angle) and a recycle delay of $3 \cdot 1$ s. For the quantification of lactate, formate was used as a concentration standard, the recycle delay was increased to $45.7 \mathrm{~s}$ and 96 transients were acquired. Carbon and phosphorus chemical shifts were referred to the resonances of external methanol or external $85 \% \mathrm{H}_{3} \mathrm{PO}_{4}$, designated at $49 \cdot 3$ p.p.m. and 0.0 p.p.m., respectively.

Enzyme activity measurements. The extracts used for measurement of enzyme activities were prepared from cells harvested in the mid-exponential growth phase (Neves et al., 2000). Enzyme activities were assayed in a spectrophotometer 
(Beckman DU70), equipped with a cell compartment thermostated at $30{ }^{\circ} \mathrm{C}$, in a total volume of $1 \mathrm{ml}$. One unit of enzyme activity was defined as the amount of enzyme catalysing the conversion of $1 \mu \mathrm{mol}$ substrate $\min ^{-1}$ under the experimental conditions used.

$\mathrm{LDH}$ and pyruvate kinase (PK) were assayed as described by Garrigues et al. (1997). The forward (Mtl1P $\rightarrow \mathrm{F} 6 \mathrm{P})$ and reverse $(\mathrm{F} 6 \mathrm{P} \rightarrow \mathrm{Mtl} 1 \mathrm{P})$ reactions catalysed by $\mathrm{Mtl}$ PDH were assayed as reported previously (Neves et al., 2000). Phosphofructokinase (PFK) activity was measured by the method of Fordyce et al. (1982). LDH activity in the $\mathrm{LDH}^{\mathrm{d}}$ strain grown on mannitol was measured by ${ }^{1} \mathrm{H}-\mathrm{NMR}$ by monitoring the rate of lactate production after the addition of sodium pyruvate $(20 \mathrm{mM})$ to a reaction mixture containing $35 \mathrm{mM}$ Tris $/ \mathrm{HCl}$ buffer, pH 7.2, $2.5 \mathrm{mM} \mathrm{MgCl}_{2}, 0.6 \mathrm{mM}$ NADH, $3 \mathrm{mM}$ FBP (activator of $\mathrm{LDH})$ and $25 \%(\mathrm{v} / \mathrm{v}){ }^{2} \mathrm{H}_{2} \mathrm{O}$. Anaerobic conditions were used to avoid NADH oxidation by the NADH oxidases present in the cell extracts.

Chemicals. $\left[1-{ }^{13} \mathrm{C}\right]$ Glucose $(99 \%$ enrichment $)$ and $\left[1-{ }^{13} \mathrm{C}\right] \mathrm{man}-$ nitol $(99 \%)$ were obtained from Campro Scientific. Formic acid (sodium salt) and methylphosphonic acid were purchased from Merck and Aldrich, respectively. All other chemicals were reagent grade.

\section{RESULTS}

\section{Characterization of growth of $\mathrm{LDH}^{\mathrm{d}}$ and MG1363 strains on mannitol}

(i) Biomass and product formation. The growth profile and the kinetics of product formation during growth of both strains under anaerobic conditions in medium containing mannitol or glucose are depicted in Fig. 1. In the $\mathrm{LDH}^{\mathrm{d}}$ construct, the major end products from mannitol $(60 \mathrm{mM})$ catabolism were formate $(94 \mathrm{mM})$, ethanol $(70 \mathrm{mM})$ and acetate $(22 \mathrm{mM})$; a minor amount of lactate $(4.8 \mathrm{mM})$ was also detected. When growth ceased, after about $18 \mathrm{~h}$ incubation, only $68 \%$ of the mannitol supplied had been consumed. Nonetheless, it is interesting to note that mannitol utilization proceeded beyond growth cessation (Fig. 1a). With glucose $(58 \mathrm{mM})$ as substrate, growth stopped only after glucose exhaustion, and a mixture of formate $(83 \mathrm{mM})$, ethanol $(60 \mathrm{mM})$, acetate $(26 \mathrm{mM})$, acetoin $(11 \mathrm{mM})$ and lactate $(10 \mathrm{mM})$ was produced. Interestingly, a small amount of mannitol (maximal extracellular concentration of $0.4 \mathrm{mM}$ ) was transiently detected in the exponential growth phase (Fig. 1, b).

In MG1363, a shift from a typical homolactic fermentation of glucose (more than $90 \%$ lactate produced) to mixed acid fermentation was observed with mannitol. The predominant end products were formate $(27 \mathrm{mM})$, ethanol $(23 \mathrm{mM})$ and lactate $(14 \mathrm{mM})$. Only $32 \%$ of the mannitol supplied was consumed (Fig. 1c).

(ii) Growth yields and energetics. In both strains studied, growth on mannitol led to the synthesis of less biomass (Fig. 1) and was characterized by lower specific growth $\left(\mu_{\max }\right)$ and substrate consumption $\left(q_{\mathrm{s}}^{\max }\right)$ rates than those observed in glucose-containing medium (Table 1). A similar biomass yield, i.e. the growth yield relative to the substrate consumed, was determined for the $\mathrm{LDH}^{\mathrm{d}}$ construct growing on glucose or mannitol and MG1363 growing on glucose; in contrast, a considerably lower value was found for the latter strain with mannitol as energy source. The global yields of ATP were calculated from the fermentation products assuming that all ATP was synthesized by substrate-level phosphorylation. In both strains, the higher ATP yield in mannitol-grown cells reflected the increased acetate production per mole substrate consumed, when compared to glucose-grown cells. Consequently, the biomass yield relative to ATP $\left(Y_{\mathrm{ATP}}\right)$, in $\mathrm{g}$ biomass (mol ATP $)^{-1}$, was higher on glucose when compared to mannitol, showing that the latter is a poorer substrate for growth. The $Y_{\mathrm{ATP}}$ values determined with glucose as energy source were equivalent to those reported previously for L. lactis (Nóvak et al., 1997).

(iii) Pools of intracellular metabolites. In the mid-exponential phase, the pool of glycolytic intermediates in MG1363 consisted mainly of FBP and 3-PGA + PEP, whereas $\mathrm{LDH}^{\mathrm{d}}$ cells growing on glucose also accumulated Mtl1P (approx. $10 \mathrm{mM}$ ) (Fig. 2). In mannitolcontaining medium, both strains accumulated large amounts of Mtl1P (above $20 \mathrm{mM}$ ) and FBP (above $30 \mathrm{mM}$ ), indicating the presence of bottlenecks at the two NADH-generating steps [Mtl1P and glyceraldehyde-3-phosphate (GAP) dehydrogenases]. In the late-exponential phase, Mtl1P was still the predominant metabolite, except in glucose-grown MG1363 cells, where 3-PGA + PEP were the only intermediates detected. The presence of FBP and Mtl1P in extracts obtained in the late exponential phase reflects the availability of mannitol or glucose at the time of sampling (see arrows in graphs of Fig. 1), except for strain MG1363 grown on glucose for which the substrate was already depleted.

\section{In vivo ${ }^{13} \mathrm{C}-\mathrm{NMR}$ studies}

(i) Influence of growth substrate on mannitol metabolism by LDH $^{\mathbf{d}}$ strain. Fig. 3 shows the kinetics of substrate consumption/end product formation and the pools of intracellular metabolites during mannitol catabolism by glucose-grown $\mathrm{LDH}^{\mathrm{d}}$ cells. The products formed were ethanol $(18.0 \pm 1 \cdot 0 \mathrm{mM})$, lactate $(5 \cdot 4 \pm 0.2 \mathrm{mM})$, acetate $(2 \cdot 4 \pm 0 \cdot 3 \mathrm{mM})$ and 2,3-butanediol (1.9 $\pm 0 \cdot 1 \mathrm{mM})$ (Fig. 3a). Additionally, a high amount of unlabelled formate $(25.9 \pm 1 \mathrm{mM})$ was measured by ${ }^{1} \mathrm{H}-\mathrm{NMR}$ in the total cell extracts resulting from these experiments. The mannitol consumption rate was approx. $0.03 \mu \mathrm{mol}$ $\min ^{-1}$ (mg protein) ${ }^{-1}$, 3.6-fold lower than the rate of

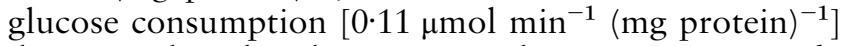
determined under the same conditions (Neves et al., 2000). The build-up of the Mtl1P pool was fast during the first $10 \mathrm{~min}$ and continued at a slower rate while mannitol was available, reaching a maximal concentration of $100 \pm 1 \mathrm{mM}$ (Fig. 3b). After mannitol exhaustion, Mtl1P decreased to undetectable levels at a rate similar to that of mannitol consumption. The FBP pool became detectable (around $3 \mathrm{mM}$ ) during the period of slow accumulation of Mtl1P and increased transiently to 

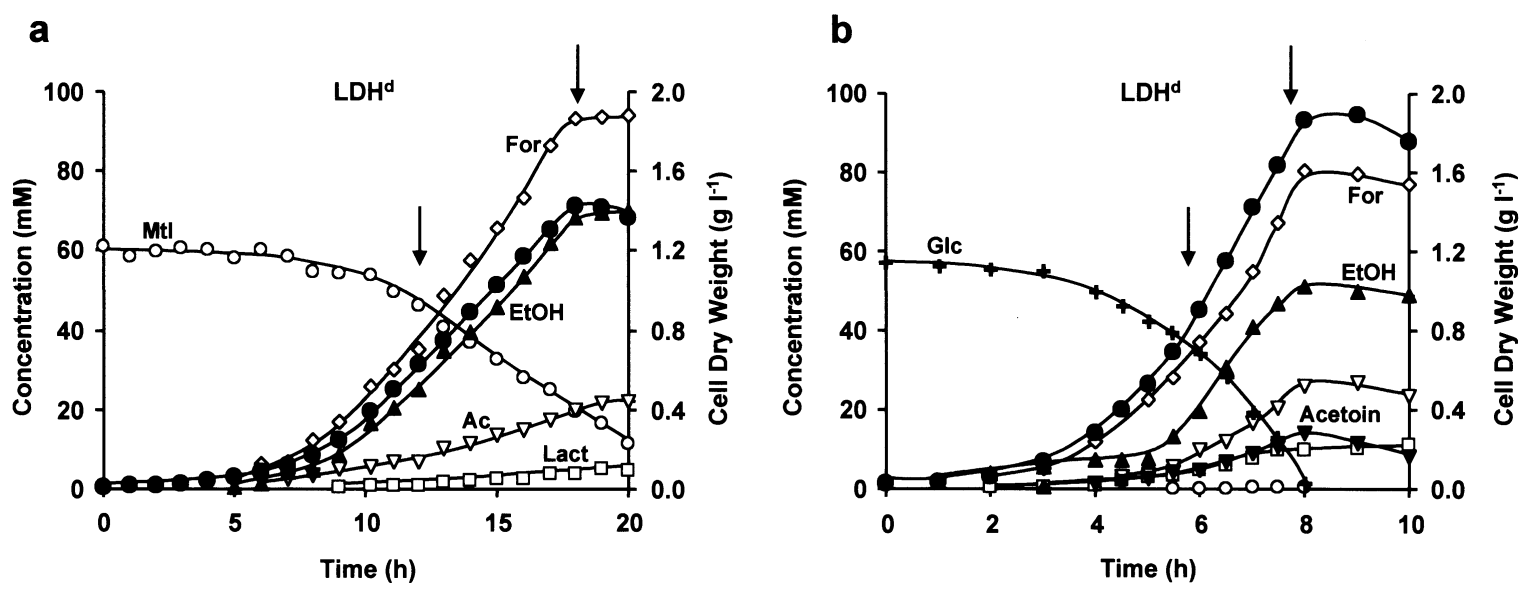

C

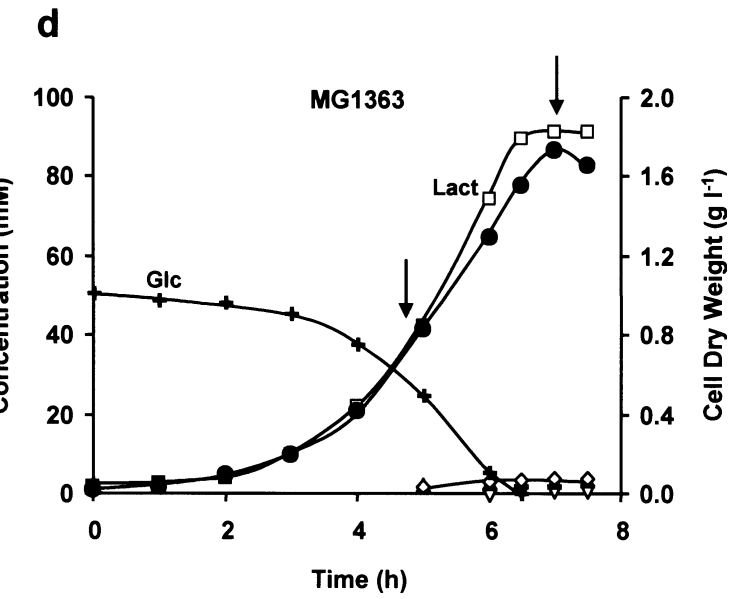

Fig. 1. Growth curves, substrate consumption and end product formation by $\operatorname{LDH}^{\mathrm{d}}$ ( $a$ and b) and MG1363 (c and d) strains growing under anaerobiosis on mannitol ( $a$ and $c$ ) or glucose (b and d). Symbols: + , glucose; $\bigcirc$, mannitol; $\square$, lactate; $\boldsymbol{\Lambda}$, ethanol; $\boldsymbol{\nabla}$, acetoin; $\nabla$, acetate; $\diamond$, formate; $\boldsymbol{\theta}$, biomass. For the sake of clarity the following labels were included in the graphs: EtOH, ethanol; Glc, glucose; Mtl, mannitol; Lact, lactate; Ac, Acetate; For, formate. The arrows indicate the times at which samples were withdrawn for ethanol extraction and quantification of phosphorylated metabolites.

Table 1. Carbon and redox balances, specific growth rate $\left(\mu_{\max }\right)$, and growth and energetic parameters obtained for $\mathrm{LDH}^{\mathrm{d}}$ and MG1363 strains cultured on glucose or mannitol

\begin{tabular}{|lccccc|}
\hline \multirow{2}{*}{ Parameter } & \multicolumn{2}{c}{ LDH $^{\mathrm{d}}$} & & \multicolumn{2}{c|}{ MG1363 } \\
\cline { 2 - 3 } \cline { 6 - 6 } & Glucose & Mannitol & & Glucose & Mannitol \\
\hline Carbon balance & 97 & 97 & & 95 & 105 \\
Redox balance & 97 & 97 & & 97 & 106 \\
$\mu_{\max }\left(\mathrm{h}^{-1}\right)$ & $0 \cdot 95$ & $0 \cdot 55$ & & $1 \cdot 15$ & $0 \cdot 42$ \\
Biomass yield $\left[\mathrm{g}(\mathrm{mol} \mathrm{substrate})^{-1}\right]$ & $33 \cdot 4$ & $34 \cdot 1$ & & $34 \cdot 2$ & $25 \cdot 1$ \\
ATP yield $\left[\mathrm{mol}(\mathrm{mol} \mathrm{substrate})^{-1}\right]$ & $2 \cdot 41$ & $2 \cdot 69$ & & $1 \cdot 89$ & $2 \cdot 23$ \\
$Y_{\mathrm{ATP}}\left[{\left.\mathrm{g} \mathrm{biomass}(\mathrm{mol} \mathrm{ATP})^{-1}\right]}^{\max }\right.$ & $13 \cdot 4$ & $12 \cdot 7$ & & $18 \cdot 1$ & $11 \cdot 3$ \\
$q_{\mathrm{s}}^{\max }\left(\mathrm{mmol} \mathrm{g}^{-1} \mathrm{~h}^{-1}\right)$ & $11 \cdot 9$ & $4 \cdot 9$ & & $18 \cdot 3$ & $5 \cdot 8$ \\
\hline
\end{tabular}

a maximal concentration of $7 \pm 1 \mathrm{mM}$ during Mtl1P consumption. Meanwhile, the 3-PGA pool started to increase slowly and levelled off at $33 \pm 3 \mathrm{mM}$, whereas PEP accumulation $(7 \pm 2 \mathrm{mM})$ was observed only after
FBP depletion. At the onset of mannitol exhaustion, aspartate and pyruvate reached concentrations of $14 \pm 2 \mathrm{mM}$ and $10 \pm 3 \mathrm{mM}$, respectively. Thereafter, pyruvate decreased slowly to a final concentration of 
a

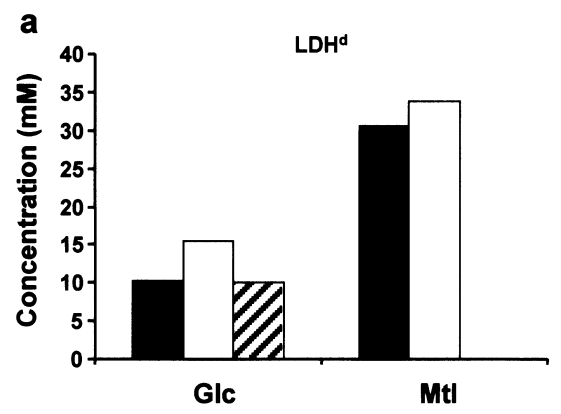

C

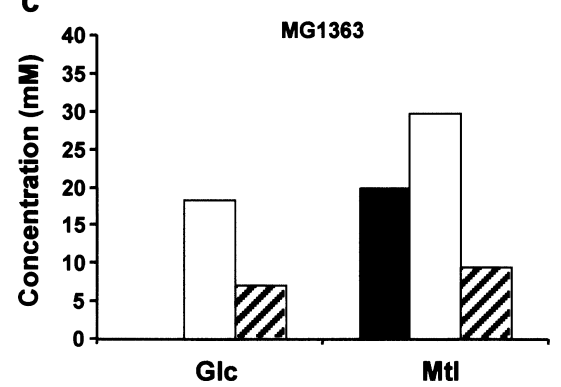

b

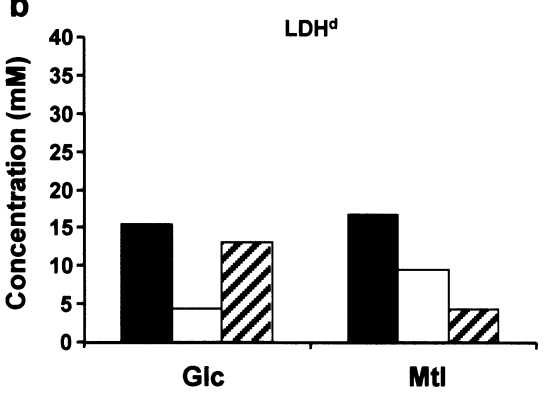

d

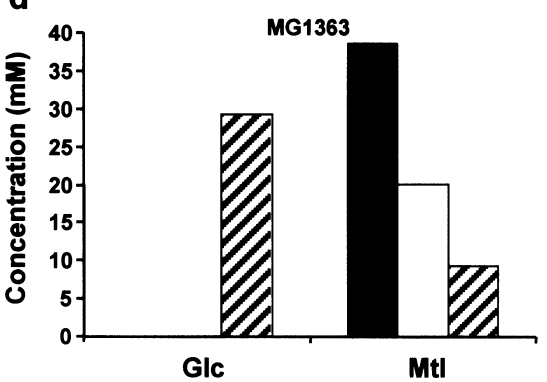

Fig. 2. Intracellular concentrations of glycolytic intermediates in ethanol extracts of the $\operatorname{LDH}^{\mathrm{d}}$ (a and b) and MG1363 ( $c$ and d) strains harvested at mid-exponential ( $a$ and c) and late-exponential (b and d) growth phases. $\square$, Mtl1P; $\square$, FBP; $\square, 3-P G A+P E P$.

about $5 \mathrm{mM}$. Other minor metabolites, such as succinate $(1.4 \mathrm{mM})$ and 2-PGA $(2.4 \mathrm{mM})$, were also detected in the cell extracts (not shown).

In mannitol-grown $\mathrm{LDH}^{\mathrm{d}}$ cells, the rate of mannitol consumption was only $1 \cdot 3$-fold higher than that observed in glucose-grown cultures. A similar pattern of end products was found: ethanol $(18.5 \pm 2 \mathrm{mM})$, lactate (5.5 $\pm 0.2 \mathrm{mM}), 2,3$-butanediol $(2 \cdot 9 \pm 0.2 \mathrm{mM})$, acetate $(1.3 \pm 0.3 \mathrm{mM})$ and formate $(23.0 \pm 1.0 \mathrm{mM})$ (Fig. $4 \mathrm{a})$. Nevertheless, significant differences were observed in the kinetics of intracellular metabolites (Fig. 4b). Immediately after mannitol addition, the fast accumulation of Mtl1P $(63 \pm 1 \mathrm{mM})$ was followed by a transient decrease to $48 \pm 1 \mathrm{mM}$; at this stage, FBP increased from undetectable levels to a steady concentration of $18 \pm 1 \mathrm{mM}$. During the subsequent 30 minutes, the Mtl1P pool increased and reached a maximal concentration of $79 \pm 1 \mathrm{mM}$. After mannitol depletion, while the Mtl1P pool declined, a transient increase in the FBP concentration to $24 \cdot 5 \pm 0.5 \mathrm{mM}$ was observed. 3 -PGA reached a concentration of $43 \pm 5 \mathrm{mM}$, and it is interesting to note that the rate of accumulation of this metabolite was much faster when the cells were grown on mannitol. The PEP pool was only visible long after mannitol addition, reaching a maximal concentration of $10 \pm 3 \mathrm{mM}$. Pyruvate accumulated $(4 \pm 1 \mathrm{mM})$ while mannitol was available, decreasing afterwards to undetectable levels (not shown).

(ii) Glucose metabolism in the $\mathrm{LDH}^{\mathrm{d}}$ strain grown on mannitol. The metabolism of $\left[1-{ }^{13} \mathrm{C}\right]$ glucose by cell suspensions of the mannitol-grown $\mathrm{LDH}^{\mathrm{d}}$ construct was also studied by in vivo NMR (Fig. 5). Glucose was consumed at a rate of $0.08 \mu \mathrm{mol} \mathrm{min}{ }^{-1}(\mathrm{mg} \text { protein })^{-1}$ with equimolar amounts of ethanol $(8 \cdot 6 \pm 0.4 \mathrm{mM})$ and 2,3-butanediol $(9 \cdot 6 \pm 0 \cdot 8 \mathrm{mM})$ being produced. Lactate $(2 \cdot 3 \pm 0 \cdot 1 \mathrm{mM})$ and acetoin $(1 \cdot 3 \pm 0 \cdot 2 \mathrm{mM})$ were also detected. Particularly interesting was the notable increase in the production of 2,3-butanediol when glucose was supplied. The formation of one molecule of 2,3butanediol requires the oxidation of one NADH per mannitol consumed, whereas four NADH molecules are oxidized when ethanol is produced. The relief of the pressure to regenerate $\mathrm{NAD}^{+}$, enabled by the transient production of mannitol, was also apparent from the accumulation of acetoin, which is derived from pyruvate in a non-redox reaction. The increased competitiveness of the 2,3-butanediol/acetoin pathway could be explained by the presumed activation of $\alpha$-acetolactate synthase (an enzyme with low affinity for pyruvate) by a higher pyruvate pool associated with the twofold higher glycolytic flux when glucose was the substrate. However, this view is not supported by our experimental data that shows a much higher pyruvate pool when mannitol was the substrate. Importantly, production of 2,3-butanediol was not observed during growth on glucose (Fig. 1b).

Mannitol, Mtl1P and FBP were observed immediately upon the addition of glucose (Fig. 5b). As long as glucose was available, mannitol increased to a concentration of $58 \pm 1 \mathrm{mM}$; at the onset of glucose exhaustion the mannitol pool decreased sharply, originating a transient increase of Mtl1P. Our previous work has shown that about one-fourth of the mannitol derived from glucose 
a

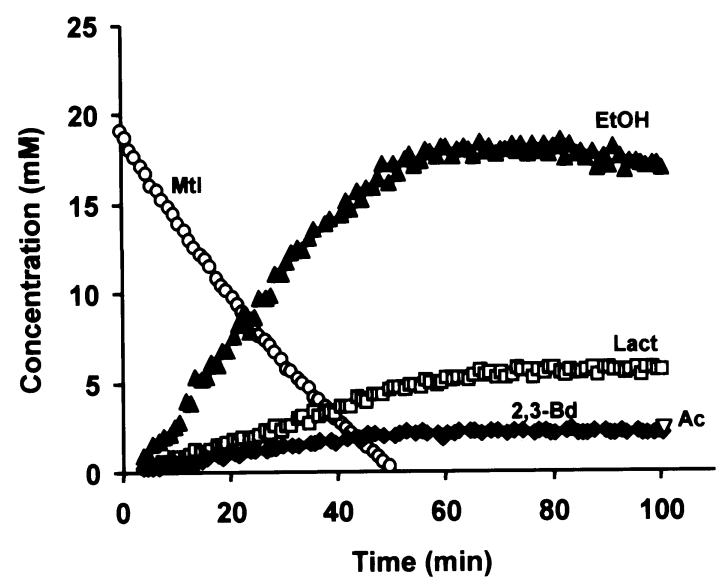

b

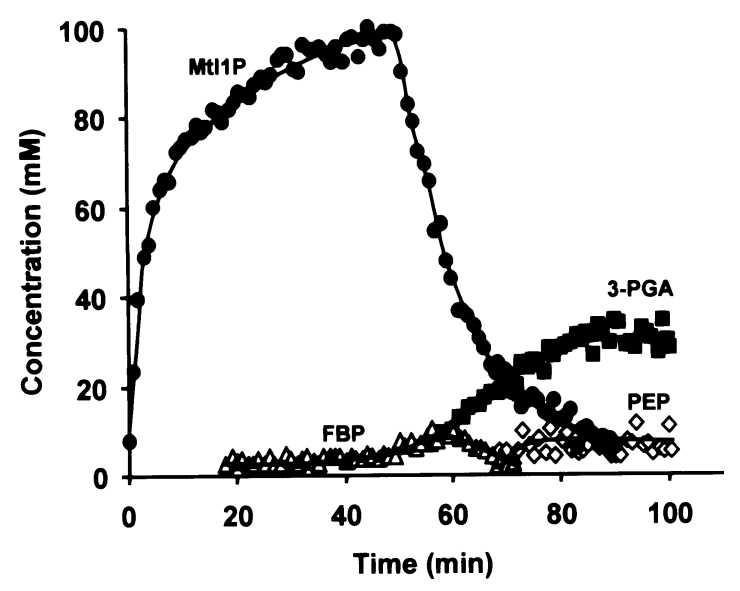

Fig. 3. Kinetics of $\left[1^{13} \mathrm{C}\right]$ mannitol consumption and product formation by $\mathrm{LDH}^{d}$ cells grown on glucose (a) and pools of intracellular metabolites (b) under argon atmosphere as determined by in vivo ${ }^{13} \mathrm{C}$-NMR. Symbols: $\bigcirc$, mannitol; $\square$, lactate; $\boldsymbol{\Delta}$, ethanol; $\nabla$, acetate; $\diamond, 2,3$-butanediol; $\triangle, F B P ; \mathbf{\square}$, $3-P G A ; \diamond, P E P ; 0, M t 11 P$. For the sake of clarity the following labels were included in the graphs: $\mathrm{EtOH}$, ethanol; $\mathrm{Mtl}$, mannitol; 2,3-Bd, 2,3-butanediol; Lact, lactate; Ac, Acetate. Fitted lines are simple interpolations.

is secreted to the external medium (Neves et al., 2000). Therefore, the transient accumulation of Mtl1P is interpreted as being due to the utilization of mannitol upon glucose depletion. FBP increased transiently during Mtl1P depletion and subsequently decreased to undetectable levels. Concomitantly, 3-PGA and PEP increased and reached concentrations of $41 \pm 2$ and $16 \pm 2 \mathrm{mM}$, respectively.

\section{In vitro measurements of enzyme activities}

Specific activities of relevant enzymes were measured in crude extracts obtained from mid-exponential cultures of mannitol-grown $\mathrm{LDH}^{\mathrm{d}}$ and MG1363 (Table 2) and were compared to the activities measured in glucose- a

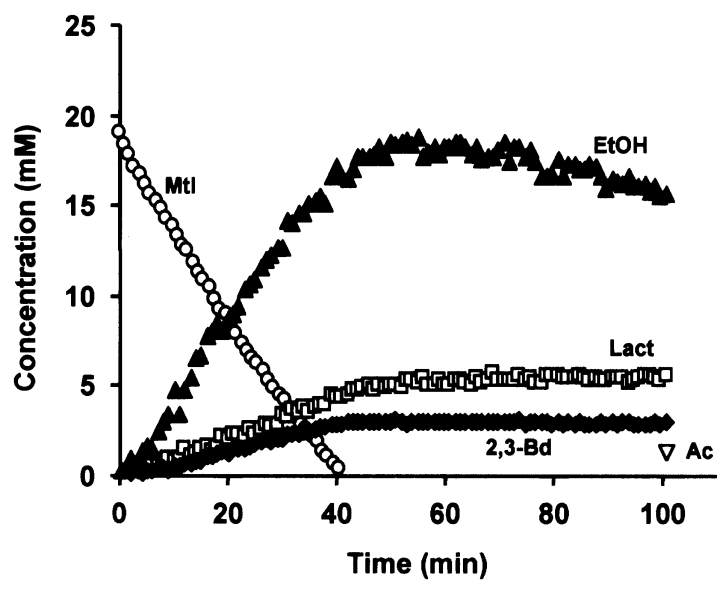

b

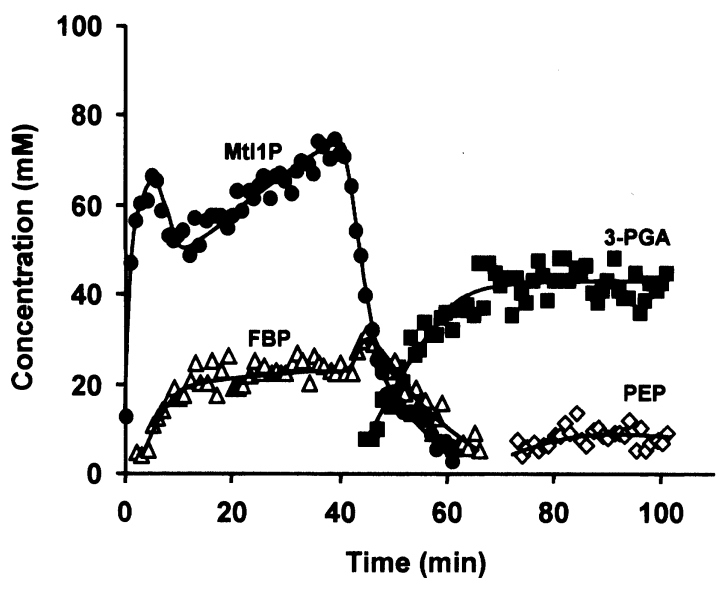

Fig. 4. Kinetics of $\left[1{ }^{13} \mathrm{C}\right]$ mannitol consumption and product formation by $\mathrm{LDH}^{\mathrm{d}}$ cells grown on mannitol (a) and pools of intracellular metabolites (b) under argon atmosphere as determined by in vivo ${ }^{13} \mathrm{C}$-NMR. Symbols are as defined in the legend to Fig. 3. Fitted lines are simple interpolations.

grown cells reported previously (Neves et al., 2000). LDH activity $[10.5 \mathrm{U} \text { (mg protein })^{-1}$ in the MG1363 strain grown on mannitol was lower than that reported for glucose-grown cells $\left.[16 \cdot 1 \mathrm{U} \text { (mg protein })^{-1}\right]$. Furthermore, the lactate-producing activity determined in extracts of the $\mathrm{LDH}^{\mathrm{d}}$ construct was reduced 40-fold upon growth on mannitol. This low 'LDH' activity was measured by ${ }^{1} \mathrm{H}-\mathrm{NMR}$ in extracts of mannitol-grown cultures, since the sensitivity of the standard spectrophotometric method coupled to NADH oxidation was too low to allow detection. Interestingly, PFK and PK, enzymes encoded by the same operon as LDH, were reduced by about $1 \cdot 4$-fold in the $\mathrm{LDH}^{\mathrm{d}}$ strain grown on mannitol when compared to glucose-grown cultures (Neves et al., 2000).

The activity of Mtl1PDH in extracts obtained from glucose-grown $\mathrm{LDH}^{\mathrm{d}}$ cells was measured in the forward and reverse directions and found to be 0.83 and $0.68 \mathrm{U}$ 
a

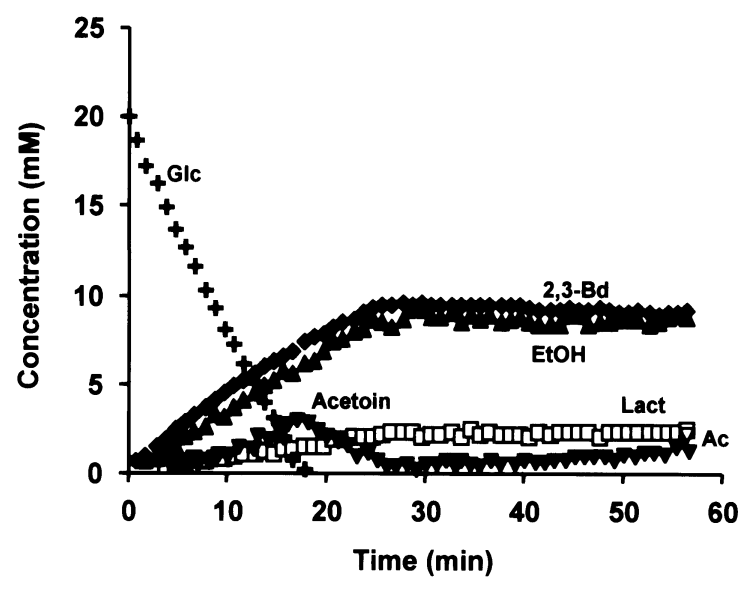

b

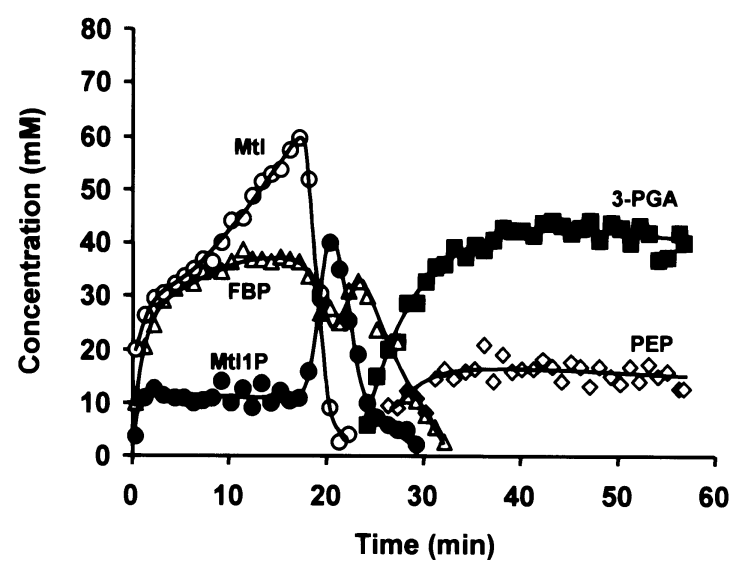

Fig. 5. Kinetics of $\left[1-{ }^{13} \mathrm{C}\right]$ glucose consumption and product formation by $\mathrm{LDH}^{\mathrm{d}}$ cells grown on mannitol (a) and pools of intracellular metabolites (b) under argon atmosphere as determined by in vivo ${ }^{13} \mathrm{C}-\mathrm{NMR}$. Symbols: + , glucose; $\square$, lactate; $\boldsymbol{\Delta}$, ethanol; $\boldsymbol{\nabla}$, acetoin; $\nabla$, acetate; $\bullet, 2,3-$ butanediol; $\triangle$, FBP; $\square, 3-P G A ; \diamond$, PEP; O, mannitol; $\bullet$, Mtl1P. For the sake of clarity the following labels were included in the graphs: EtOH, ethanol; Glc, glucose; Mtl, mannitol; 2,3-Bd, 2,3butanediol; Lact, lactate; Ac, Acetate. Fitted lines are simple interpolations. (mg protein $)^{-1}$, respectively (Neves et al., 2000). The results in Table 2 show that growth on mannitol strongly induced Mtl1PDH, since much higher activities were found in both strains when grown on mannitol. The effect of NADH on the activity of Mtl1PDH was also assessed. Concentrations of $0.2,0.4$ and $0.6 \mathrm{mM}$ caused, respectively, 26, 47 and $64 \%$ reduction of the activity.

\section{DISCUSSION}

The potential biotechnological applications of mannitol in the food industry triggered the elucidation of mannitol metabolism in the starter bacterium L. lactis. This work shows that both the $\mathrm{LDH}^{\mathrm{d}}$ strain and the parental strain, MG1363, were able to use mannitol as a source of energy for growth, although higher $Y_{\mathrm{ATP}}$ values, specific growth rates and substrate consumption rates were achieved in glucose. In L. lactis, mannitol is most likely transported by a PEP:PTS ${ }^{\mathrm{Mtl}}$. In fact, an operon ( $m$ tlARFD) encoding proteins with high sequence similarity to EIICB $^{\mathrm{MTL}}$, MtlR, EIIA ${ }^{\mathrm{MTL}}$ and Mtl1PDH of other organisms has been identified in the genome of L. lactis (Bolotin et al., 2001). Furthermore, a L. lactis ptsH1 mutant strain in which the phosphorylated Ser-46 of HPr was replaced with an alanine, lost the capacity to grow on mannitol, suggesting that this polyol is transported by a PTS (Monedero et al., 2001). After mannitol transport and concomitant phosphorylation, the resulting Mtl1P is oxidized to F6P via Mtl1PDH with production of NADH (Fig. 6). This NADH burden probably creates a strong obstruction to mannitol metabolism and is responsible for the lower performance of mannitol in supporting growth of L. lactis. In fact, the accumulation of large amounts of Mtl1P during growth on mannitol, and also in non-growing cells metabolizing mannitol (Figs 2-4), suggests the existence of a major bottleneck at the level of Mtl1PDH. In agreement with this interpretation, the pool of Mtl1P decreased significantly in mannitol-grown $\mathrm{LDH}^{\mathrm{d}}$ cells as compared to glucose-grown $\mathrm{LDH}^{\mathrm{d}}$ cells, reflecting the sixfold increase in the activity of Mtl1PDH. However, a considerable impairment at Mtl1PDH persists, since the rate of mannitol consumption increased by only $30 \%$ in man-

Table 2. Enzyme activities [U (mg protein $)^{-1}$ ] determined in crude cell extracts of strains MG1363 and LDH ${ }^{\mathrm{d}}$ grown on mannitol

All the determinations were done at least in triplicate in two extracts obtained from independent cultures; mean accuracy $\pm 5 \%$. ND, Not detected; -, not determined. Activities measured in glucosegrown cells were reported previously by Neves et al. (2000). f, forward; r, reverse.

\begin{tabular}{|c|c|c|c|c|}
\hline \multirow[t]{2}{*}{ Enzyme } & \multicolumn{2}{|c|}{ MG1363 } & \multicolumn{2}{|c|}{$\mathrm{LDH}^{\mathrm{d}}$} \\
\hline & Mannitol & Glucose & Mannitol & Glucose \\
\hline $\mathrm{Mtl} \mathrm{PDH}^{\mathrm{f}}$ & 6.77 & $\mathrm{ND}$ & $4 \cdot 91$ & $0 \cdot 83$ \\
\hline $\mathrm{Mtl} \mathrm{PDH}^{\mathrm{r}}$ & $4 \cdot 44$ & $0 \cdot 02$ & $3 \cdot 73$ & $0 \cdot 68$ \\
\hline LDH & $10 \cdot 54$ & $16 \cdot 12$ & $0 \cdot 006$ & $0 \cdot 25$ \\
\hline PK & - & 1.52 & $0 \cdot 99$ & $1 \cdot 36$ \\
\hline PFK & - & $0 \cdot 96$ & $0 \cdot 71$ & $0 \cdot 96$ \\
\hline
\end{tabular}




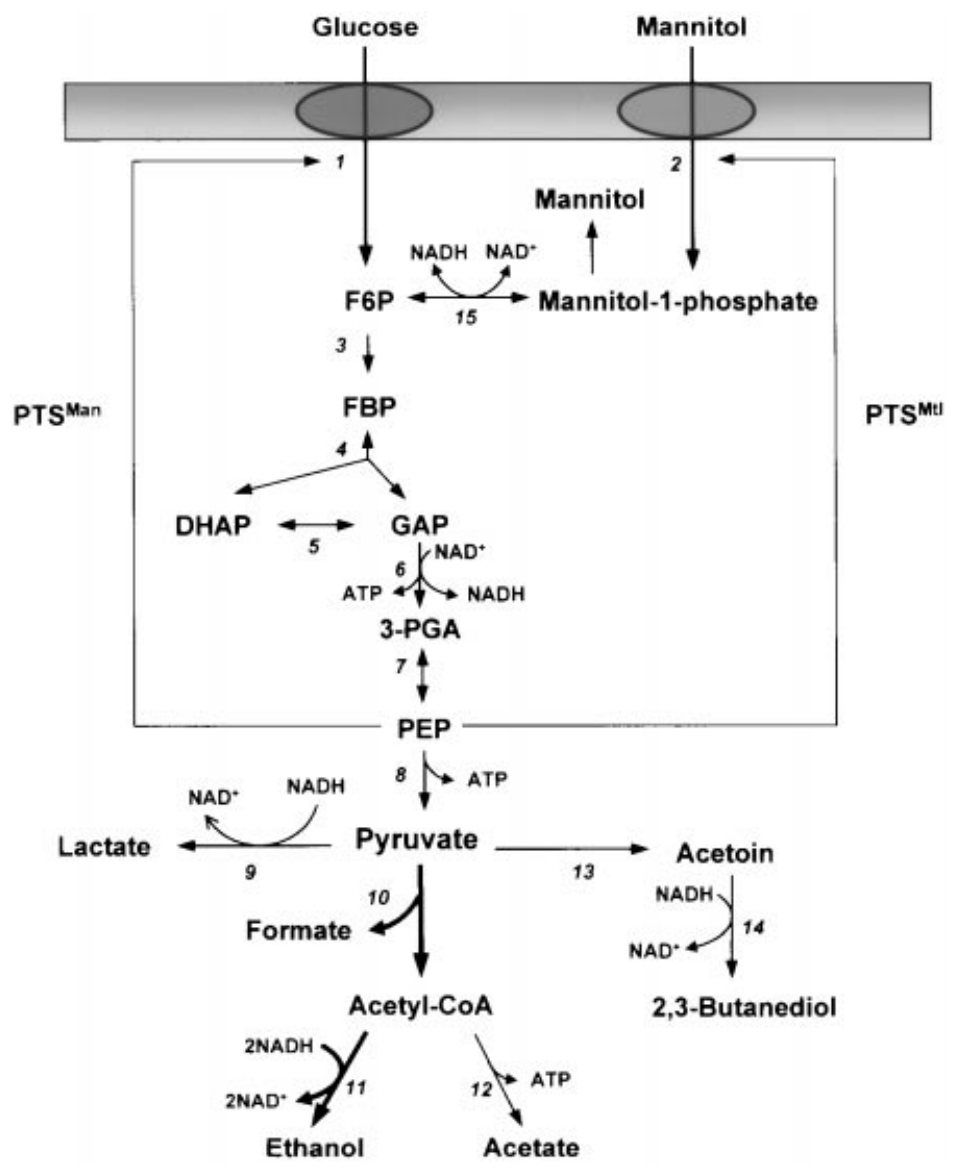

Fig. 6. Pathways of mannitol and glucose catabolism by $L$. lactis. The reactions indicated are catalysed by the following enzymes: 1, mannose-dependent phosphotransferase system and phosphoglucose isomerase; 2, PTS ${ }^{\mathrm{Mtl}}$; 3, PFK; 4, FBP aldolase; 5, triosephosphate isomerase; 6, GAPDH and phosphoglycerate kinase; 7 , phosphoglyceromutase and enolase; 8, PK; 9, LDH; 10, pyruvate-formate lyase; 11 , acetaldehyde dehydrogenase and alcohol dehydrogenase; 12 , acetate kinase; $13, \alpha$-acetolactate synthase and $\alpha$-acetolactate decarboxylase; 14, 2,3-butanediol dehydrogenase; 15, Mtl1PDH.

nitol-grown cells. The relative sizes of the Mtl1P and FBP pools in resting cells, the Mtl1P pool being much higher than that of FBP, and the drastic decrease of FBP in glucose-grown cells constitutes additional evidence for the position of the main bottleneck upstream of the reaction catalysed by GAPDH. The remarkable accumulation of Mtl1P, which reaches concentrations of the order of $100 \mathrm{mM}$ in non-growing cells, could be in part due to inhibition of Mtl1PDH by NADH accumulation, since in vitro this enzyme is considerably inhibited by this coenzyme, a feature also described for GAPDH (Even et al., 1999; Neves et al., 2002). Accumulation of $\mathrm{NADH}$ up to $2.5 \mathrm{mM}$ was recently determined in vivo in an $\mathrm{LDH}^{\mathrm{d}}$ strain derived from L. lactis MG1363 by gene replacement during the metabolism of glucose (Neves et al., 2002).

In contrast to the results obtained for the kinetics of the FBP pool, which reaches a steady level whilst glucose is available (Neves et al., 1999), the Mtl1P pool increases continuously, although at a slower rate, after the initial steep accumulation (Figs 3 and 4). A plausible explanation could be substrate inhibition of Mtl1PDH by Mtl1P. The kinetic mechanism of Aspergillus niger Mtl1PDH was proposed to be a random bi-bi mechanism with two dead-end complexes (Kiser \& Niehaus, 1981). Therefore, if both Mtl1P and NADH accumulate above a certain level, an inactive enzyme-Mtl1P-NADH complex is formed, and consequently the amount of active enzyme will be reduced.

A significant production of lactate by the $\mathrm{LDH}^{\mathrm{d}}$ strain was observed under all conditions tested. This construct possesses two dysfunctional truncated copies of the $l d h$ gene. One is under the control of the las promoter and the other has no promoter unless there is readthrough from the integrated plasmid (Gasson et al., 1996). The activity measured is either due to one of these copies, or more likely, to a distinct LDH, since four genes showing sequence homology with $l d h$ genes from other organisms are present in the genome of L. lactis IL1403 (Bolotin et al., 2001). The latter hypothesis is probably correct, since an LDH-deficient strain obtained by a single crossover deletion of the $l d h$ gene in L. lactis MG1614 still produced lactate and a different LDH was isolated from that strain (Gaspar, P., Coelho, P., Neves, A. R., Shearman, C., Gasson, M. J., Ramos, A. \& Santos, H., unpublished results). Interestingly, the lactate-producing activity measured in extracts of mannitol-grown cells was 40-fold lower when compared to glucosegrown cells, but the mechanisms underlying this phenomenon, also observed in MG1363 extracts although to a lesser extent (1.5-fold reduction of $\mathrm{LDH}$ activity), are unknown. LDH and PK activities are also lower in L. lactis cells grown on galactose when compared to glucose, and this was believed to be due to reduced 
transcriptional activation of the las operon by the carbon catabolite protein A, CcpA (Luesink et al., 1998). It was suggested that this could be a consequence of lower intracellular G6P and FBP, which were found to enhance the binding of CcpA to DNA in Bacillus subtilis (Deutscher et al., 1995; Miwa et al., 1997). However, a different explanation must hold for L. lactis, since we have found higher FBP levels in mannitol-grown cells than in glucose-grown cells (Fig. 2).

Also intriguing is the poor utilization of mannitol for growth of MG1363 when compared to $\mathrm{LDH}^{\mathrm{d}}$, which exhibits reasonably good growth yields on this substrate (Fig. 1). This suggests that the disruption of the $l d h$ gene per se induced the expression of genes implicated in mannitol transport and metabolism in the $\mathrm{LDH}^{\mathrm{d}}$ strain. Mtl1PDH, a key enzyme for mannitol utilization, was enhanced by at least 34-fold (compare activities of glucose-grown cells in Table 2), and the glucose-grown parental strain was unable to utilize mannitol (not shown), whereas comparable consumption rates were observed in the $\mathrm{LDH}^{\mathrm{d}}$ strain regardless of the growth substrate.

A striking feature in the composition of the end products derived from mannitol by the $\mathrm{LDH}^{\mathrm{d}}$ strain was the considerable accumulation of ethanol, with $50 \%$ of the pyruvate being converted to this alcohol. This is the expected response to the higher pressure to oxidize $\mathrm{NADH}$, since ethanol provides the most efficient pathway for the disposal of reducing power. What is surprising is the minor production of lactate during growth of MG1363 in mannitol despite the very high activity of LDH (Table 2), the main site for NADH oxidation in this organism during the utilization of more natural substrates, such as glucose. At present, the drastic change of the carbon flux distribution at the pyruvate node remains elusive.

Given the potential impact of mannitol in the development of healthier food products, the synthesis of mannitol in L. lactis is a desirable metabolic trait. The insight into mannitol and glucose metabolism gained from the present work discloses the $\mathrm{LDH}^{\mathrm{d}}$ strain as an adequate genetic background to proceed with a metabolic engineering approach aimed at the enhancement of the in situ production of mannitol. The construction of a mannitol overproducer would have to take into account the ability of L. lactis to use mannitol as energy source. Since the uptake of mannitol is mediated by a PEP:PTS (Bolotin et al., 2001; Monedero et al., 2001) we propose that such a strain could be obtained by knocking out the mtlA gene encoding the transport protein $\left(\mathrm{EII}^{\mathrm{Mtl}}\right)$. Work is in progress in our team to attain this goal.

\section{ACKNOWLEDGEMENTS}

We thank Cristina Leitão for assistance in HPLC determinations. This work was supported by the BIOTECH Program, contract BIO4CT-96-0498 of the Commission of the European Community and by Fundação para a Ciência e Tecnologia (FCT), Portugal, contract PRAXIS/PCNA/P/
BIO/39/96. A. R. Neves and A. Ramos acknowledge FCT for the award of research fellowships.

\section{REFERENCES}

Bolotin, A., Wincker, P., Mauger, S., Jaillon, O., Malarme, K., Weissenbach, J., Ehrlich, S. D. \& Sorokin, A. (2001). The complete genome sequence of lactic acid bacterium Lactococcus lactis ssp. lactis IL1403. Genome Res 11, 731-753.

Chakravorty, M. (1964). Metabolism of mannitol and induction of mannitol 1-phosphate dehydrogenase in Lactobacillus plantarum. J Bacteriol 87, 1246-1248.

Deutscher, J., Kuster, E., Bergstedt, U., Charrier, V. \& Hillen, W. (1995). Protein kinase-dependent $\mathrm{HPr} / \mathrm{CcpA}$ interaction links glycolytic activity to carbon catabolite repression in gram-positive bacteria. Mol Microbiol 15, 1049-1053.

de Vries, W. \& Stouthamer, A. H. (1968). Fermentation of glucose, lactose, galactose, mannitol, and xylose by bifidobacteria. $J \mathrm{Bac}$ teriol 96, 472-478.

Dols, M., Chraibi, W., Remaud-Simeon, M., Lindley, N. D. \& Monsan, P. F. (1997). Growth and energetics of Leuconostoc mesenteroides NRRL B-1299 during metabolism of various sugars and their consequences for dextransucrase production. Appl Environ Microbiol 63, 2159-2165.

Edwards, K. G., Blumenthal, H. J., Khan, M. \& Slodki, M. E. (1981). Intracellular mannitol, a product of glucose metabolism in staphylococci. J Bacteriol 146, 1020-1029.

Efiuvwevwere, B. J. O., Gorris, L. G. M., Smid, E. J. \& Kets, E. P. W. (1999). Mannitol-enhanced survival of Lactococcus lactis subjected to drying. Appl Microbiol Biotechnol 51, 100-104.

Even, S., Garrigues, C., Loubiere, P., Lindley, N. D. \& CocaignBousquet, M. (1999). Pyruvate metabolism in Lactococcus lactis is dependent upon glyceraldehyde-3-phosphate dehydrogenase activity. Metab Eng 1, 198-205.

Ezra, F. S., Lucas, D. S., Mustacich, R. V. \& Russell, A. F. (1983). Phosphorus-31 and carbon-13 nuclear magnetic resonance studies of anaerobic glucose metabolism and lactate transport in Staphylococcus aureus cells. Biochemistry 22, 3841-3849.

Fordyce, A. M., Moore, C. H. \& Pritchard, G. G. (1982). Phosphofructokinase from Streptococcus lactis. Methods Enzymol 90, 77-82.

Furia, T. E. (1972). Handbook of Food Additives, 2nd edn. West Palm Beach, FL: CRC Press.

Garrigues, C., Loubiere, P., Lindley, N. D. \& Cocaign-Bousquet, M. (1997). Control of the shift from homolactic acid to mixed-acid fermentation in Lactococcus lactis: predominant role of the $\mathrm{NADH} / \mathrm{NAD}^{+}$ratio. J Bacteriol 179, 5282-5287.

Gasson, M. J. (1983). Plasmid complements of Streptococcus lactis NCDO 712 and other lactic streptococci after protoplastinduced curing. J Bacteriol 154, 1-9.

Gasson, M. J., Benson, K., Swindel, S. \& Griffin, H. (1996). Metabolic engineering of the Lactococcus lactis diacetyl pathway. Lait 76, 33-40.

Grobben, G. J., Peters, S. W., Wisselink, H. W., Weusthuis, R. A., Hoefnagel, M. H., Hugenholtz, J. \& Eggink, G. (2001). Spontaneous formation of a mannitol-producing variant of Leuconostoc pseudomesenteroides grown in the presence of fructose. Appl Environ Microbiol 67, 2867-2870.

Hugenholtz, J. \& Starrenburg, M. J. C. (1992). Diacetyl production by different strains of Lactococcus lactis subsp. lactis var. diacetylactis and Leuconostoc spp. Appl Microbiol Biotechnol 38, $17-22$. 
Hult, K., Veide, A. \& Gatenbeck, S. (1980). The distribution of the NADPH regenerating mannitol cycle among fungal species. Arch Microbiol 128, 253-255.

Kets, E. P. W., Galinski, E. A., de Wit, M., de Bont, J. A. M. \& Heipieper, H. J. (1996). Mannitol, a novel bacterial compatible solute in Pseudomonas putida S12. J Bacteriol 178, 6665-6670.

Kiser, R. C. \& Niehaus, W. G. J. (1981). Purification and kinetic characterization of mannitol-1-phosphate dehydrogenase from Aspergillus niger. Arch Biochem Biophys 211, 613-621.

Lee, C. A., Jacobson, G. R. \& Saier, M. H., Jr. (1981). Plasmiddirected synthesis of enzymes required for D-mannitol transport and utilization in Escherichia coli. Proc Natl Acad Sci US A 78, 7336-7340.

Loesche, W. J. \& Kornman, K. S. (1976). Production of mannitol by Streptococcus mutans. Arch Oral Biol 21, 551-553.

Luesink, E. J., van Herpen, R. E., Grossiord, B. P., Kuipers, O. P. \& de Vos, W. M. (1998). Transcriptional activation of the glycolytic las operon and catabolite repression of the gal operon in Lactococcus lactis are mediated by the catabolite control protein CcpA. Mol Microbiol 30, 789-798.

Luxo, C., Nobre, M. F. \& da Costa, M. S. (1993). Intracellular polyol accumulation by yeast-like fungi. Can J Microbiol 39, 868-873.

Maryanski, J. H. \& Wittenberger, C. L. (1975). Mannitol transport in Streptococcus mutans. J Bacteriol 124, 1475-1481.

Miwa, Y., Nagura, K., Eguchi, S., Fukuda, H., Deutscher, J. \& Fujita, Y. (1997). Catabolite repression of the Bacillus subtilis gnt operon exerted by two catabolite-responsive elements. Mol Microbiol 23, 1203-1213.

Monedero, V., Kuipers, O. P., Jamet, E. \& Deutscher, J. (2001). Regulatory functions of serine-46-phosphorylated HPr in Lactococcus lactis. J Bacteriol 183, 3391-3398.

Neves, A. R., Ramos, A., Nunes, M. C., Kleerebezem, M., Hugenholtz, J., de Vos, W. M., Almeida, J. \& Santos, H. (1999). In vivo nuclear magnetic resonance studies of glycolytic kinetics in Lactococcus lactis. Biotechnol Bioeng 64, 200-212.

Neves, A. R., Ramos, A., Shearman, C., Gasson, M. J., Almeida, J. S. \& Santos, H. (2000). Metabolic characterization of Lactococcus lactis deficient in lactate dehydrogenase using in vivo ${ }^{13}$ C-NMR. Eur J Biochem 267, 3859-3868.

Neves, A. R., Ventura, R., Mansour, N., Shearman, C., Gasson, M. J., Maycock, C., Ramos, A. \& Santos, H. (2002). Is the glycolytic flux in Lactococcus lactis primarily controlled by the redox charge? Kinetics of $\mathrm{NAD}^{+}$and $\mathrm{NADH}$ pools determined in vivo by ${ }^{13} \mathrm{C}$ NMR. J Biol Chem 277, 28088-28098.
Nóvak, L., Cocaign-Bousquet, M., Lindley, N. D. \& Loubiere, P. (1997). Metabolism and energetics of Lactococcus lactis during growth in complex or synthetic media. Appl Environ Microbiol 63, 2665-2670.

Poolman, B. \& Konings, W. N. (1988). Relation of growth of Streptococcus lactis and Streptococcus cremoris to amino acid transport. J Bacteriol 170, 700-707.

Poolman, B., Smid, E. J., Veldkamp, H. \& Konings, W. N. (1987). Bioenergetic consequences of lactose starvation for continuously cultured Streptococcus cremoris. J Bacteriol 169, 1460-1468.

Postma, P. W., Lengeler, J. W. \& Jacobson, G. R. (1993). Phosphoenolpyruvate:carbohydrate phosphotransferase systems of bacteria. Microbiol Rev 57, 543-594.

Rager, M. N., Binet, M. R. \& Bouvet, O. M. (1999). ${ }^{31} \mathrm{P}$ and ${ }^{13} \mathrm{C}$ nuclear magnetic resonance studies of metabolic pathways in Pasteurella multocida characterization of a new mannitolproducing metabolic pathway. Eur J Biochem 263, 695-701.

Ramos, A. \& Santos, H. (1996). Citrate and sugar cofermentation in Leuconostoc oenos, a ${ }^{13} \mathrm{C}$ nuclear magnetic resonance study. Appl Environ Microbiol 62, 2577-2585.

Ramos, A., Boels, I. C., de Vos, W. M. \& Santos, H. (2001). Relationship between glycolysis and exopolysaccharide biosynthesis in Lactococcus lactis. Appl Environ Microbiol 67, 33-41.

Rosenberg, H., Pearce, S. M., Hardy, C. M. \& Jacomb, P. A. (1984). Rapid turnover of mannitol-1-phosphate in Escherichia coli. J Bacteriol 158, 63-68.

Rozenberg-Arska, M., Van Asbeck, B. S., Martens, T. F. \& Verhoef, J. (1985). Damage to chromosomal and plasmid DNA by toxic oxygen species. J Gen Microbiol 131, 3325-3330.

Streekstra, H., Buurman, E.T., Hoitink, C. W. G., de Mattos, M. J. T., Neijssel, O. M. \& Tempest, D. W. (1987). Fermentation shifts and metabolic reactivity during anaerobic carbon-limited growth of Klebsiella aerogenes NCTC 418 in fructose, gluconate, mannitol and pyruvate. Arch Microbiol 148, 137-143.

van Munster, I. P. \& Nagengast, F. M. (1993). The role of carbohydrate fermentation in colon cancer prevention. Scand J Gastroenterol Suppl 200, 80-86.

Yamada, T. (1987). Regulation of glycolysis in streptococci. In Sugar Transport and Metabolism in Gram-positive Bacteria, pp. 69-93. Edited by J. Reizer \& A. Peterkofsky. Chichester: Ellis Horwood.

Received 18 March 2002; revised 28 June 2002; accepted 8 July 2002. 